\title{
Water at COP25: Resilience enables climate change adaptation through better planning, governance and finance
}

\author{
Julien J. Harou \\ Department of Mechanical, Aerospace and Civil Engineering, \\ The University of Manchester, Manchester, UK; \\ Department of Civil, Environmental and Geomatic Engineering, \\ University College London, London, UK \\ John H. Matthews \\ Alliance for Global Water Adaptation (AGWA), Corvallis, Oregon, USA \\ D. Mark Smith \\ International Water Management Institute (IWMI), Colombo, Sri Lanka \\ Rachael A. McDonnell \\ International Water Management Institute (IWMI), Rome, Italy \\ Edoardo Borgomeo \\ UN Food and Agricultural Organisation (FAO), Rome, Italy \\ Jennifer J. Sara \\ The World Bank, Washington, DC, USA \\ Judith Plummer Braeckman \\ University of Cambridge Institute for Sustainable Leadership (CISL), \\ Cambridge, UK \\ Nathanial Matthews \\ Global Resilience Partnership, Stockholm, Sweden
}

James Dalton

International Union for Conservation of Nature (IUCN), Gland, Switzerland Mike D. Young

Centre for Global Food and Resources, The University of Adelaide, Adelaide, Australia

\section{Henk W. J. Ovink}

Special Envoy for International Water Affairs, Kingdom of The Netherlands Musonda Mumba

Terrestrial Ecosystems Unit, UN Environment Programme, Nairobi, Kenya Martin Shouler

Arup, London, UK

\section{Sanna Markkanen}

University of Cambridge Institute for Sustainable Leadership (CISL), Cambridge, UK

\section{Sebastian Vicuña}

Department of Hydraulic and Environmental Engineering \& Centro Interdisciplinario de Cambio Global, Pontificia Universidad Católica de Chile, Santiago, Chile

\section{Introduction}

The United Nations (UN) Framework Convention on Climate Change (UNFCCC) was adopted in 1992 and governments have participated since then in its decision-making body, the 'Conference of the Parties' (COP). Chile presided over the 25th annual COP held December 2019 in Madrid, Spain. While COPs necessarily emphasise energy negotiations and carbon mitigation policies, water is an increasingly prominent topic because of the need for water in energy production and its importance in nature-based and engineered adaptation and mitigation solutions. Climate-change-induced water impacts are key considerations in, for example, infrastructure planning under changing flood and drought risk, changing agricultural practices and hydropower. Already ninety percent of all-natural disasters are water related.

Water topics featured at many sessions and meetings of COP25, with the Alliance for Global Water Adaptation (AGWA) counting over 25 water-related sessions. Uncertain changes to the variability, timing and availability of water, and water's links across economic sectors, including food and energy production and transportation, imply that the ability of countries to realise their climate ambitions and address climate risks depends on water management and planning as an adaptation strategy. With effective climate policies and tools, countries can avoid increased regional and sectoral resource conflicts, social and economic disruption, environmental degradation and internal and international political conflict over water. Many COP25 sessions asked how should water be addressed in national climate plans? Below we briefly review some reports relevant to water management published in the run-up to COP25, and then summarise overarching themes discussed during the event.

\section{Some water documents discussed at COP25}

The Global Commission on Adaptation's (GCA) foundational report (GCA, 2019) starts provocatively: 'Will we delay and pay more or plan ahead and prosper?' Seeking a triple dividend in the form of net economic, social and environmental benefits, the GCA recommends a global investment of US\$1.8 trillion between 2020 and 2030 in early warning systems, climate-resilient infrastructure, improved dryland agricultural production, and global mangrove protection for an estimated $\$ 7 \cdot 1$ trillion in net benefits. To increase adaptation's pace and scale, three 'revolutions' are required in $(i)$ understanding (consider who and what is at risk in decision-making); (ii) planning (improve policy and investment decisions considering uncertainty and multidimensional performance); and (iii) finance (increased pace and scale of public and private financing, better metrics and disclosure). In the water space, GCA calls for better climate and hydrological risk assessments at every level of planning and operation, as well as the development of efficient water allocation systems to manage scarcity.

The main GCA report was accompanied by a series of background papers, many of which addressed water topics directly or indirectly. The background paper on water considers the topic of climate-resilient water adaptation, asking questions like 'how do we ensure that our climate actions will be effective 
in the face of emerging and uncertain impacts?' and 'what can the water community do to help advance climate change targets, and the climate community to help advance water resilience targets?' (Smith et al., 2019). Climate change is reconfiguring the water systems that interconnect water users in urban and rural areas with the energy, agricultural and industrial sectors and with nature. Water managers need to re-examine institutions, strategies, planning and investment to increase the resilience of water infrastructure, regulatory frameworks, water-sharing agreements and water allocation schemes. As past water data alone can no longer be used to assess future investments, resilience in an uncertain future is achieved through robustness (interventions perform acceptably across a range of plausible futures) and flexibility (investments are adaptable). The paper proposes actions on governance, information, design and management that recognise the need for equity and co-design in water adaptation, and to rethink how finance and economic instruments can better serve and enable water adaptation.

The GCA background paper on infrastructure suggests that US $\$ 80$ trillion of investment in new and existing infrastructure is required worldwide in the next 15 years (Hall et al., 2019). Without care, decisions made now could lock in risks for decades to come, threaten the viability of infrastructure investments and burden countries with escalating economic and human impacts and repair costs. The paper examines the evidence for adaptation to climate change within infrastructure systems, including reviewing climate risks to infrastructure, the current state of adaptation and barriers to adaptation. It lists steps to adapt existing infrastructure systems to make them more resilient to a changing climate and examines how, in future, infrastructure could be planned, designed and delivered. Enhancing the resilience of infrastructure systems requires securing their performance in a changing climate and enhancing the planning for sustainable infrastructure development.

In the GCA background paper on landscape management, Seth and Scherr (2019) argue that to integrate adaptation actions across sectors and stakeholders, farmers, land managers, policy makers, civil society organisations, business leaders and investors should address common challenges at the local landscape scale through integrated landscape management (ILM). ILM integrates adaptation across agriculture, water, biodiversity, urban settlements and fisheries. Effective ILM includes institutions enabling multi-stakeholder and multi-sector coordination; a structured process for multi-sector landscape assessment, goal-setting and planning; farm and landscape interventions aiming for synergies; public policies and programs aligned to support integrated adaptation and development; and finance mobilised for a coordinated investment portfolio. Integration should be addressed from source to sea, as climate risks to coastal communities will have impacts inland across agriculture, infrastructure and cities, and vice versa.
Other GCA background papers with relevance to the points discussed below included Miller and Swann (2019) on finance for climate resilience, Jarzabkowski et al. (2019) on insurance as a financial instrument, Hallegatte et al. (2019) on aligning climate change adaptation with development, Van Schaik et al. (2019) on adaptation and conflict resolution, and Resurrección et al. (2019) on gender and equity.

Besides the GCA papers, other recent reports addressing water and climate change were discussed at COP25. Timboe et al. (2019) of AGWA argue that by adopting resilient and lowcarbon water management approaches that combine robustness and flexibility, parties to the UNFCCC can fulfil nationally determined contribution (NDC) commitments and ensure that their climate policies and actions foster synergies rather than conflict. The paper provides evidence, examples and tools for managing water in ways that contribute to achieving the Paris Agreement, along with a set of principles and recommendations for updating and implementing national climate plans.

The Netherlands Environmental Assessment Agency (Ligtvoet et al., 2018) presented a Geography of Future Water Challenges, showing that - under a business-as-usual 2050 scenario exacerbated by climate change - global population growth, further economic development and related increases in pressure on the ecological environment will increase global water-related risks.

The Nature Conservancy (Matthews et al., 2019) featured their report on source-water protection as a tool for enabling resilience and climate change adaptation. Source waters can deliver reliable and high-quality water services for drinking and domestic use, livestock and ranching, irrigation, energy, industrial development, and disaster prevention and recovery.

The Inter-American Development Bank (IDB) and partners published a Framework and Principles for Climate Resilience Metrics in Financing Operations (IDB, 2019). It conceptualises and gives examples of metrics to define and report on the contribution of financing activities toward climate-resilience objectives. They qualitatively or quantitatively express the change in climate resilience resulting from specific project activities. Some are related to project design (e.g. diagnostics, inputs and activities), others are based on project results (e.g. outputs, outcomes and impacts) and others are hybrids (measuring both the resilience of projects and the resilience gained systemwide as a result of the intervention). Metrics can be evaluated before ('ex ante' analysis) or after projects.

The Global Water Partnership (Young, 2019) offers a framework and a set of questions designed to assist local communities and water managers considering the need for improving existing water-sharing arrangements. It describes a way of assessing water-sharing systems and transitioning when necessary to better-performing arrangements. 
To address the need for cities to build resilience, Arup (2019) and partners published the City Water Resilience Approach (CWRA). It can be used by public and private organisations, national and regional government representatives, cities, utilities, catchment and basin authorities, the private sector and civil society groups. CWRA aims to build water resilience by providing high-quality water resources for all residents, protecting them from water-related hazards and connecting them through water-based transportation networks.

\section{Some water themes at COP25}

A few themes emerged at COP25 and in the reports published beforehand. Adapting water resource systems and their users to a changing climate and other changes will be an increasingly essential political, social, environmental and economic imperative. The goal is to equip people and societies with the ability to make the adjustments across systems, sectors and scales needed to anticipate, withstand and recover from the impacts of climate change. Incentives for avoiding losses and securing benefits are strong, but how can these be achieved?

Adaptation through increased resilience was a dominant theme of COP25. Resilience is an expression of society's ability to function, recover and thrive under stress that emerges through improved institutions, knowledge, incentives, infrastructure, ecosystems and social constructs. Smith et al. (2019) define resilience in this context as the ability to adjust, recover or reorganise in response to climate change impacts. Resilience becomes essential when global water supplies become nonstationary (trends in water availability change over time) and more generally if supply and demand become subject to 'deep' uncertainty - predictions (probabilities of future supply and demand) cannot easily be known and agreed upon. Under such uncertainty, optimally weighing alternative decisions according to their expected outcomes, the classical engineering-economic approach to planning, becomes less appropriate. Instead, the best options for managing water become those that are robust because they show satisfactory performance across a wide range of possible futures. Equally, if the future can evolve in ways which are unexpected, being able to adjust and respond to unexpected developments and trends via flexibility (or 'adaptability') is of value. In fact, robustness and flexibility - the building blocks of resilience- should be considered not just in water management and planning, but in the design of infrastructure, institutions and policies more generally (Hall et al., 2019; Smith et al., 2019). If adapting water resource systems to climate change happens through enhancing and enabling resilience, how then to achieve this level of robustness and adaptability? Several enabling factors were discussed in COP25 sessions and documents; below we explore three of them: planning, governance and finance.

Several GCA background papers outline the opportunity and necessity for improved planning, its approaches and processes, to reach resilience goals. This relates to better understanding of how benefits, costs and risks are distributed spatially and over time in resource systems like water, as a basis for providing better information on how climate change impacts manifest. With integrated investment-to-impact assessment tools in hand, new multi-dimensional participatory system-scale planning methods can be used that explicitly consider supply, demand and other uncertainties to evaluate interventions. Interventions include policies and/or assets like built or natural infrastructure, viewed as development or adaptation options. 'Multi-dimensional' refers to the fact that several performance metrics (also called 'measures' or 'indices') are considered, such as service levels for water provision to all economic water-using sectors (including the environment) and all relevant spatial entities (service areas, landscapes, regions, countries, etc). 'Participatory' implies co-creation of water plans with representative stakeholders rather than consultation or other top-down forms of planning. In this case, planning aims to be open, transparent and participative, becoming more like 'strategic co-design' and includes iterative system-scale integrated stakeholder assessment of interventions and their trajectories (over time). When diverse and representative stakeholder groups work together to achieve broadly acceptable outcomes, co-creation results and the adoption of such planning approaches becomes governance change.

Governance was identified in several COP25 sessions as an essential enabler of good water-climate outcomes and a key resilience catalyst. In this context, the efficacy of governance reflects the ability to set and enforce effective policies that help achieve sustainable outcomes under poorly predictable change. The objective is to mainstream climate change considerations into water management, and further into development and economic policies (Hallegatte et al., 2019). The main GCA report suggests political leaders must foster collaboration among government agencies and openly involve other actors (private sector, civil society, the public), put in place effective planning and regulatory regimes, and support management of transboundary waters through cooperation among states based upon agreements and joint management bodies. COP25 sessions also discussed the governance responsibilities of water managers: $(i)$ propose and articulate policies and investments to decision-makers that enable development despite unknown climate and other changes; (ii) prioritise investments for leaders to fund, based on their ability to costeffectively achieve high social, environmental and economic value; and (iii) help other resource system policy-makers (energy, food, environment, etc) appreciate water linkages to facilitate effective and efficient cross-sector policies and collaboration.

One expression of the effectiveness of water governance is its ability to create a stable environment for financing of selected interventions and projects, including measures to improve resilience. Financing for public goods (e.g. urban drainage, flood control, environmental quality, etc) is typically made 
available by the public sector (GCA, 2019), while water users fund water supply and wastewater infrastructure. Financial products and services (e.g. insurance) should enable societies to 'share' unexpected costs so that they are not absorbed by people and organisations alone. Climate-labelled finance (CBI, 2020) and climate-proofed finance, where water risks are considered, can help financiers direct funds to investments that have a positive cumulative impact on climate and water outcomes. COP25 built momentum behind the idea that the water sector must assist and enable the creation of new financial products to manage risks and direct finance to projects that achieve good outcomes at system-scale - and in doing so, contribute to the UN Sustainable Development Goals and enable both mitigation and adaptation.

\section{Conclusion}

Increasing resilience of water-environment-human systems (i.e., improving their robustness and adaptability) is key to enabling climate change adaptation. Resilience can be achieved through improved planning, delivered by open and strategic co-design, more effective and responsive water governance, and finance and financial services that align investment incentives with increased system-scale resilience. Water can be an enabling component in NDCs, helping countries meet their goals for climate change mitigation and adaptation.

\section{REFERENCES}

Arup (2019) The City Water Resilience Approach. Arup, London, UK. See https://www.arup.com/perspectives/city-water-resilienceapproach (accessed 06/03/2020).

CBI (Climate Bonds Initiative) (2020) 2019 Green Bond Market Summary. CBI, London, UK. See https://www.climatebonds.net/ resources/reports/2019-green-bond-market-summary (accessed 06/03/2020).

GCA (Global Commission on Adaptation) (2019) Adapt Now: A Global Call for Leadership on Climate Resilience. GCA, Rotterdam, the Netherlands. See https:/gca.org/global-commission-on-adaptation/ report (accessed 06/03/2020).

Hall JW, Aerts JCJH, Ayyub BM et al. (2019) Adaptation of Infrastructure Systems: Background Paper for the Global Commission on Adaptation. GCA, Rotterdam, the Netherlands. See https://cdn.gca.org/assets/2019-12/GCA-Infrastructurebackground-paperV11-refs_0.pdf (accessed 06/03/2020).

Hallegatte S, Brandon C, Damania R et al. (2019) The Economics of (and Obstacles to) Aligning Development and Climate Change Adaptation. GCA, Rotterdam, the Netherlands. See https:// cdn.gca.org/assets/2018-10/18_WP_GCA_Economics_1001_final. pdf (accessed 06/03/2020).
IDB (Inter-American Development Bank) (2019) A Framework and Principles for Climate Resilience Metrics in Financing Operations. IDB, Washington, DC, USA. See https://publications.iadb.org/en/ framework-and-principles-climate-resilience-metrics-financingoperations (accessed 06/03/2020).

Jarzabkowski P, Chalkias K, Clarke D, lyahen E, Stadtmueller D and Zwick A (2019) Insurance for Climate Adaptation: Opportunities and Limitations. GCA, Rotterdam, the Netherlands. See https:/ cdn.gca.org/assets/2019-12/Insurance $\% 20$ for $\% 20$ climate $\%$ 20adaptation_Opportunities $\% 20$ and $\% 20$ Limitations.pdf (accessed 06/03/2020).

Ligtvoet W, Bouwman A, Knoop J et al. (2018) The Geography of Future Water Challenges. PBL Netherlands Environmental Assessment Agency, the Hague, the Netherlands. See https://www.pbl.nl/en/ publications/the-geography-of-future-water-challenges (accessed 06/03/2020).

Matthews J, Matthews N, Simmons E and Vigerstol K (2019) Wellspring Source Water Resilience and Climate Adaptation. The Nature Conservancy, Arlington, VA, USA. See https://www.nature.org/ content/dam/tnc/nature/en/documents/Wellspring_FULL_Report_ 2019.pdf (accessed 06/03/2020).

Miller A and Swann S (2019) Driving Finance Today for the Climate Resilient Society of Tomorrow. GCA, Rotterdam, the Netherlands. See https://cdn.gca.org/assets/2020-01/Finance_for_Climate_ Resilient_Society_GCA_Paper.pdf (accessed 06/03/2020).

Resurrección BP, Bee BA, Dankelman I et al. (2019) GenderTransformative Climate Change Adaptation: Advancing Social Equity. GCA, Rotterdam, the Netherlands. See https://cdn.gca.org/ assets/2019-12/GenderTransformativeClimateChangeAdaptation. pdf (accessed 06/03/2020).

Seth S and Scherr SJ (2019) Achieving Climate Change Adaptation through Integrated Landscape Management. GCA, Rotterdam, the Netherlands. See https://cdn.gca.org/assets/2020-03/Achieving Climate_Change_Adaptation_Through_Integrated_Landscape_ Management_-_Feb_2020.pdf (accessed 06/03/2020).

Smith DM, Matthews JH, Bharati L et al. (2019) Adaptation's Thirst: Accelerating the Convergence of Water and Climate Action. GCA, Rotterdam, the Netherlands. See https://cdn.gca.org/assets/2019-12/ AdaptationsThirst_0.pdf (accessed 06/03/2020).

Timboe I, Pharr K and Matthews JH (2019) Watering the NDCs: National Climate Planning for 2020 - How Water-Aware Climate Policies Can Strengthen Climate Change Mitigation \& Adaptation Goals. AGWA, Corvallis, OR, USA. See https://alliance4water.org/ wateringthendcs/ (accessed 06/03/2020).

Van Schaik L, Born C, Sellwood E and de Bruin S (2019) Making Peace with Climate Adaptation. GCA, Rotterdam, the Netherlands. See https://cdn.gca.org/assets/2019-12/ MakingPeaceWithClimateAdaptation_V2.pdf (accessed 06/03/2020).

Young MA (2019) Water Sharing. The Role of Robust Water Sharing Arrangements in Integrated Water Resources Management. Global Water Partnership, Stockholm, Sweden. See https://www.gwp.org/ globalassets/global/toolbox/publications/perspective-papers/ gwp-sharing-water.pdf (accessed 06/03/2020). 